Research Article

\title{
The Movement Characteristics of Coal Granular Body in Excavating Rescue Channel in the Collapsed Body
}

\author{
Hao Chuanbo, ${ }^{1}$ Liu Zhenwen $\left(\mathbb{D},{ }^{1}\right.$ Xiao Fukun $\mathbb{D}^{2},{ }^{2}$ Liu Gang $(\mathbb{D}),{ }^{2}$ and Zhang Rui ${ }^{3}{ }^{3}$ \\ ${ }^{1}$ Heilongjiang University of Science and Technology, Haerbin, Heilongjiang 150022, China \\ ${ }^{2}$ Heilongjiang Ground Pressure \& Gas Control in Deep Mining Key Lab, Heilongjiang University of Science and Technology, \\ Haerbin, Heilongjiang 150022, China \\ ${ }^{3}$ College of Mining Engineering of Hust, Heilongjiang University of Science and Technology, Haerbin, Heilongjiang 150022, China
}

Correspondence should be addressed to Xiao Fukun; xiaofukun@hotmail.com

Received 29 August 2018; Accepted 8 October 2018; Published 29 November 2018

Guest Editor: Guo-zhong $\mathrm{Hu}$

Copyright (C) 2018 Hao Chuanbo et al. This is an open access article distributed under the Creative Commons Attribution License, which permits unrestricted use, distribution, and reproduction in any medium, provided the original work is properly cited.

\begin{abstract}
The collapsed body formed after the underground power disaster is broken into loose body. The mechanical characteristics of the collapsed body are quite different from those of the homogeneous rock mass, and the rescue tunnel is affected by its moving characteristics. In this study, the lateral pressure coefficient of the collapsed body and the angle of the slip surface were deduced. The numerical experiment based on CDEM slump excavation was performed. The accumulation state of the collapsed body and the active lateral pressure coefficient and the angle of the slip surface are obtained. The characteristics of the force of the accumulation body which naturally collapsed were studied. Particle size, excavation position, excavation shape, volume, and the influence of natural repose angle on the occurrence mode and particle movement were obtained; the velocity field and slip surface of the lower left and middle lower parts during excavation and the variation of the natural repose angle were analyzed.
\end{abstract}

\section{Introduction}

In the coal mine, after the roadway falling, which was caused by the power disaster, the roof and surrounding rock collapsed to form a broken collapsed body which filled into the roadway. The collapsed body is a rock block of different sizes, a support material of loose coal and the original roadway, and a medium such as water, forming a mixture of different sizes of bulk or even water, mud, coal, and stone. In a limited space, because the collapsed body is limited by the space formed by the broken surrounding rock, its force characteristics, stress state, and damage are different. The collapsed body is mainly affected by the gravity load of itself and the interaction between the broken blocks. Rescue of mine personnel requires excavation of blocked areas, dredging roadways in complex conditions, or establishing rescue passages in the collapsed body. Secondary disasters may be caused by any unscientific excavation, which increases rescue risks and economic losses [1-4]. How to ensure the safety of the mine rescue workers and quickly form a stable channel has become the emphasis and difficulty of mine collapse accident rescue. Mastering the movement characteristics and mechanical characteristics of the excavation process has become the key to solving the problem.

The mechanism of the collapsed body can be truly grasped by the research on the occurrence state, stress characteristics, and excavation movement path of the surrounding rock collapsed accumulation body. For the study of the occurrence state, Hao et al. [3] thought that the roadway collapsed body is round and has self-organizing chimeric properties and sorting properties. Zhang et al. [5] took theoretical calculations to obtain the anchor cantilever principle and the combination principle. The collapse morphology is approximately quadrilateral. Pu et al. $[6,7]$ analyzed the collapsed body of flood roadway and obtained three types of rock mass accumulation, coal slurry deposition, and coal rock mixing. The relationship between the microscopic coefficient of bulk and macroscopic compaction was analyzed by Yan et al. [8]. The macroscopic and microscopic features and deformation localization effects of the shear force were studied by Yang et al. 
[9]. Gao et al. [10] arranged and studied the structural mechanical properties of the discrete units. Hao et al. [3] derived the lateral and longitudinal force calculation formulas of any point in the height boundary level resistance accumulation body of the falling accumulation body and gave the horizontal resistance distribution curve on the boundary of the accumulation body. In terms of the excavation and excavation movement, Liang et al. [11] studied the movement law and deformation of the slope body under the condition of support and unsupport. Zhang et al. [12] performed numerical calculations on different excavation locations and excavation shapes of the roadway's fallen body. For the study of broken slumps, in addition to theoretical analysis and experimental study of physical and mechanical properties, numerical simulation [13-22] is also an important means.

The roadway crushing zone, the falling shape, and the poststabilized stress state from the theoretical and experimental aspects were analyzed by scholars. The excavation of the slope granular body was also analyzed, but no scholars conducted integrative research on the field study, force analysis, and excavation process of the roadway collapsed body after the disaster. Based on the above, the purpose of this paper is to attempt to solve the problem of the occurrence, deformation, and movement characteristics of the excavation of the collapsed body during the emergency rescue process. Effective control of the movement of the block is supported. The aim of this study is to provide theoretical support for the safe, rapid, and effective emergency rescue after the underground coal mine disaster.

\section{Field Study}

In order to understand the morphological characteristics of the backwardness of the roadway, the body of the collapse of the roadway after the disaster occurred in a coal mine of Longmei Group (as shown in Figure 1) was obtained, which has the following characteristics:

(1) The block of the collapsed body of the surrounding rock can be regarded as a nearly spherical shape, and the dimensions in all directions are equivalent. The state after the roadway is smashed is shown in Figure 1.

(2) The roadway is degraded into a self-organizing and fitting process, and the block body of the surrounding collapsed rock body is compacted by its own weight without cementation. The side wall of the roadway only plays a limiting role, but has no supporting reaction force.

Through the survey and statistics of the collapse of the surrounding rock after several mines have been drilled, the size of the coal and rock mass in the surrounding rock fall and the proportion of the bulk of the different sizes are shown in Table 1:

For the basis of subsequent research, natural repose angle experiments of coal particles with particle sizes of $20 \mathrm{~mm}$ and $2 \mathrm{~mm}$ were carried out.
The natural repose angle is calculated as follows:

$$
\beta_{c}=\arctan \frac{2 h}{l},
$$

where $\beta_{c}$ is the natural repose angle; $h$ is the the vertical height of the surrounding rock collapse body, $\mathrm{cm}$; and $l$ is the horizontal length of the accumulation, $\mathrm{cm}$ (Figure 2).

\section{Analysis of Mechanical Characteristics of Surrounding Rock Collapsed Body}

In order to excavate the blocked roadway, it is necessary to determine the force in the horizontal direction and the vertical direction between the blocks in the surrounding rock of the roadway to determine the excavation position. The second is the characteristics of the movement of the excavation block in different areas under the accumulation state of the surrounding rock fall of the roadway.

3.1. Stress Analysis of Surrounding Rock Collapsed Body. It can be seen from the field study that the force of the accumulation body in the vertical direction is proportional to the depth, and the vertical stress of the accumulation body is calculated according to formula (2):

$$
\sigma_{y}=y \rho g .
$$

In confined space, the surrounding rock caving body is subjected to lateral compressive stress at the boundary position. By analyzing the lateral compressive stress coefficient, the lateral compressive stress at the boundary is finally obtained.

The lateral compressive stress is calculated by formula (3) under normal conditions:

$$
\sigma_{x}=n \sigma_{y},
$$

where $n$ is the lateral compressive stress coefficient; $\sigma_{y}$ is the vertical compressive stress; and $\sigma_{x}$ is the lateral compressive stress.

The lateral pressure coefficient is inconsistent under the active pressure $\left(n_{\min }\right)$ and the passive pressure $\left(n_{\max }\right)$. It is assumed that the sides of the roadway have no displacement and do not provide force to the granular rock. There is no shear stress in the vertical plane, but compressive stress, as seen in Figure 3(a).

The vertical compressive stress is represented by $P_{y}=P_{2}$, and the horizontal compressive stress is represented by $P_{x}=$ $P_{1}$.

$$
\begin{aligned}
\frac{\sigma_{x}}{\sigma_{y}}= & \frac{\left(r_{a} / \sin \varphi\right)-r_{a}}{\left(r_{a} / \sin \varphi\right)+r_{a}}=\frac{1-\sin \varphi}{1+\sin \varphi}=\frac{\sin 90^{\circ}-\sin \varphi}{\sin 90^{\circ}+\sin \varphi} \\
& =\frac{2 \sin \left(90^{\circ}-\varphi / 2\right) \cos \left(90^{\circ}+\varphi / 2\right)}{2 \sin \left(90^{\circ}+\varphi / 2\right) \cos \left(90^{\circ}-\varphi / 2\right)} \\
& =\operatorname{tg}\left(45^{\circ}-\frac{\varphi}{2}\right) \operatorname{ctg}\left(45^{\circ}+\frac{\varphi}{2}\right)=\operatorname{tg}^{2}\left(45^{\circ}-\frac{\varphi}{2}\right)=n_{\text {min }} .
\end{aligned}
$$




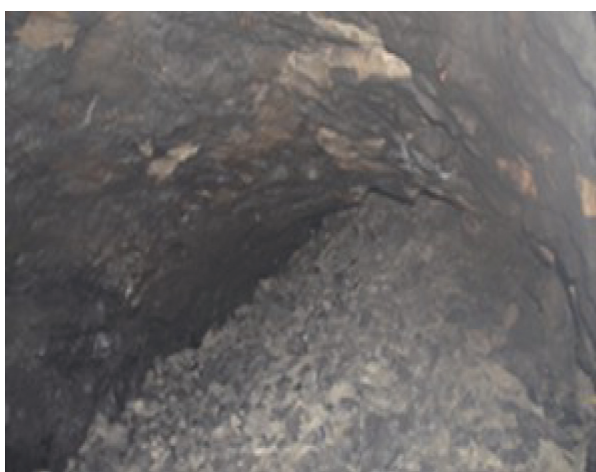

(a)

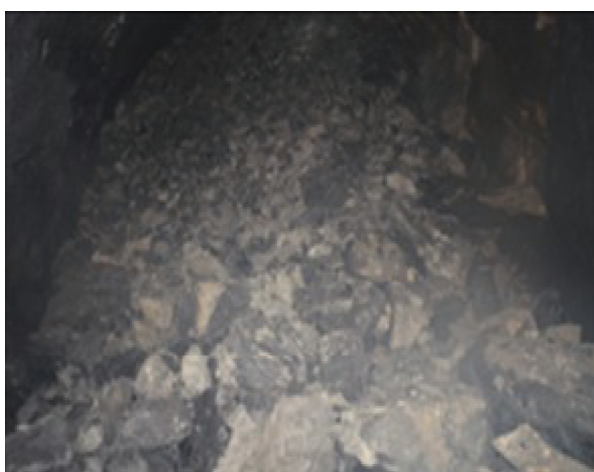

(b)

Figure 1: Roadway caving section. (a) Typical field 1. (b) Typical field 2.

TABle 1: Proportion of blocks with different sizes in surrounding rock collapse.

\begin{tabular}{lcccc}
\hline Serial number & $\begin{array}{c}\text { Maximum size of coal } \\
\text { crushing block }(\mathrm{mm})\end{array}$ & Average proportion (\%) & $\begin{array}{c}\text { Maximum size of rock } \\
\text { crushing block (mm) }\end{array}$ & Average proportion (\%) \\
\hline 1 & $\leq 10$ & 10 & $\leq 50$ & 15 \\
2 & $10-50$ & 15 & $50-100$ & 20 \\
3 & $50-100$ & 30 & $100-200$ & 30 \\
4 & $100-200$ & 30 & $200-300$ & 20 \\
5 & $\geq 200$ & 15 & $\geq 300$ & 15 \\
\hline
\end{tabular}

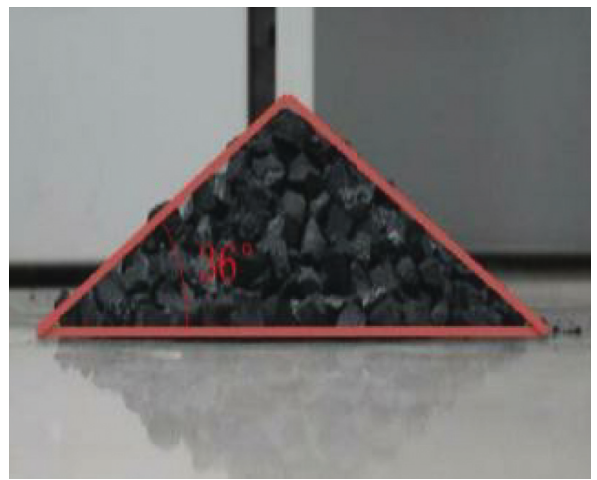

(a)

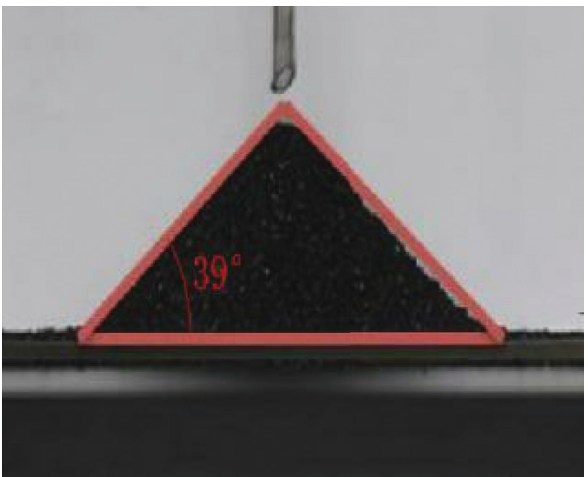

(b)

FIgURE 2: Natural repose angle of coal. (a) Coal with a particle size of $20 \mathrm{~mm}$. (b) Coal with a particle size of $2 \mathrm{~mm}$.

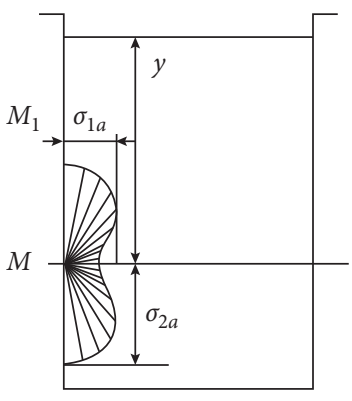

(a)

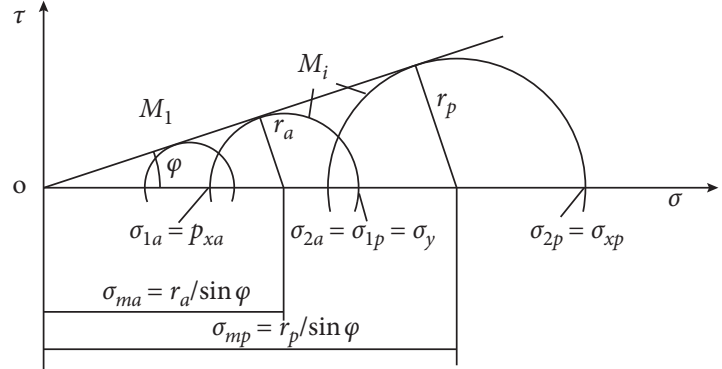

(b)

Figure 3: Horizontal lateral stress. (a) Active pressure (b) Mohr's stress circle of lateral stress coefficient. 
The horizontal pressure (literal compressive stress) at any depth $y$ in the roadway can be obtained as follows:

$$
\sigma_{x a}=y \rho g \operatorname{tg}^{2}\left(45^{\circ}-\frac{\varphi}{2}\right)=y \rho g n_{\min }
$$

where $r_{a}$ is the radius and $\varphi$ is the internal friction angle.

It can be seen from formula (5) that the lateral compressive stress is related to the internal friction angle of the surrounding rock collapsed body and is proportional to the depth. The smaller the internal friction angle is, the larger the literal stress is. When the internal friction angle approaches zero, the lateral compressive stress approaches the vertical compressive stress. At this time, the surrounding rock fall can be regarded as a fluid, and the stress is equal in all directions.

In order to calculate the $n_{\text {min }}$, the relationship between cohesion and internal friction angle is introduced here by formula (6) [23].

$$
\tau=C+\sigma \operatorname{tg} \varphi
$$

where $C$ is the cohesive force; $\tau$ is the shear stress; $\sigma$ is the positive pressure; and $\varphi$ is the internal friction angle.

Through the variable angle shear test of the coal sample, $\varphi=38.13^{\circ}, C=2.13 \mathrm{MPa}$ is obtained, and it is substituted into formula (5), $n_{\min }=\operatorname{tg}^{2}\left(45^{\circ}-38.13 / 2\right)=0.237$ is obtained. Horizontal force at any position can be obtained according to formula (5).

3.2. Analytical Solution of the Angle of the Slip Surface of the Surrounding Rock. As shown in Figure 4, when a vertical wall slips, the loose particles next to the wall will also produce a slight slip and form a slip surface. The bulk of the slip portion forms a pyramid and is supported between the vertical wall and the material slip surface. When the side wall friction is ignored, but the internal friction of the slip surface is considered, the equilibrium condition of the angular cylinder of granular body is (Figure 4(b))

$$
F_{h}=G \operatorname{tg}(\theta-\varphi) \text {, }
$$

where $F_{h}$ is the reaction force of the vertical wall to the object; $G$ is the column weight; $\theta$ is the slip surface inclination angle; and $\varphi$ is the internal friction angle.

When the wall width is unit length,

$$
G=\frac{Y^{2} \rho g \operatorname{tg}\left(90^{\circ}-\theta\right)}{2} \text {. }
$$

Bring $\operatorname{tg} \varphi=f$ in, you can get

$$
F_{h}=\frac{Y^{2} \rho g}{2} \operatorname{tg}\left(90^{\circ}-\theta\right) \operatorname{tg}(\theta-\varphi)=\frac{Y^{2} \rho g(\operatorname{tg}-f)}{2(1+f \operatorname{tg} \theta) \operatorname{tg} \theta},
$$

where $f$ is the coefficient of friction inside the material.

When the horizontal force $F_{h}$ changes, the abovementioned relationship can be satisfied for different inclination angles of slip surface. Under gravity, the slip surface will appear when the lateral deformation damages limit equilibrium. At this time, the lateral pressure is taken to the smallest when considering the most dangerous situation,

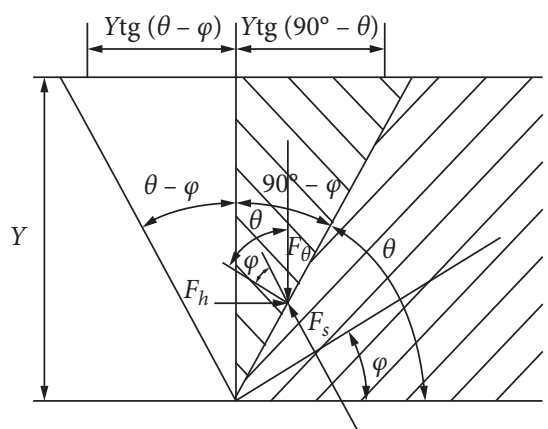

(a)

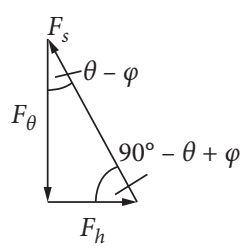

(b)
Figure 4: Analysis of the force of grains on the sliding surface. (a) Overall stress analysis. (b) Unit analysis.

and the $\theta$ angle is the angle of the slip surface. In the abovementioned formula, the auxiliary variable $x=\operatorname{tg} \theta$ is hidden and $d F_{h} / d x=0$, then

$$
\frac{x+f x^{2}-(x-f)(1+2 f x)}{\left(1+f x^{2}\right) x^{2}}=0 .
$$

Solve the equation:

$$
\begin{aligned}
x & =f+\sqrt{1+f^{2}}=\operatorname{tg} \varphi+\frac{1}{\cos \varphi}=\frac{1+\sin \varphi}{\cos \varphi} \\
& =\frac{\sin 90^{\circ}+\sin \varphi}{\cos 90^{\circ}+\cos \varphi}=\frac{2 \sin \left(90^{\circ}+\varphi / 2\right) \cos \left(90^{\circ}-\varphi / 2\right)}{2 \cos \left(90^{\circ}+\varphi / 2\right) \cos \left(90^{\circ}-\varphi / 2\right)} \\
& =\operatorname{tg}\left(45^{\circ}+\frac{\varphi}{2}\right)=\operatorname{tg} \theta .
\end{aligned}
$$

Therefore, the active slip surface angle is obtained as follows:

$$
\theta=45^{\circ}+\frac{\varphi}{2}
$$

If the limit equilibrium is not destroyed by the lateral deformation which is caused by the vertical compressive stress, but by the shear stress which is generated by the lateral compressive stress that exceeds the shear strength of the granular body, the slip surface is also formed, and the limit equilibrium state is destroyed. This type of destruction is called passive destruction. The inclination of the passive slip surface is consistent with that of the active damage. According to the theoretically derived formula, when the friction angle is $36^{\circ}$, the inclination angle of the slip surface is $63^{\circ}$.

\section{Analysis of the Characteristics of the Excavation of the Collapsed Body of the Surrounding Rock}

In order to analyze the movement law during the excavation process of the collapsed body, the discrete element simulation software (2D simulation) is used to excavate the granular body in the roadway model. The accumulation form of the granular body after excavation, the movement 
law of the particle, and the dipping angle of the excavation slip surface are analyzed.

\subsection{Establishment of the Discrete Element Model of the Col-} lapse Body and Boundary Conditions. The size of the original roadway is $3.6 \mathrm{~m}$ high and $4.2 \mathrm{~m}$ wide, which is measured at the roadway. According to the actual size of the original roadway, the $1: 1$ particle discrete element numerical model of the roadway is established. In the simulation software, monitor has the function of monitoring the spherical information of a specific spherical point, and the coordinates of the sphere $x$ and $y$ are selected. The boundary nodes' movement on both sides of the model in the $x$ direction is fixed, and the fixed bottom surface movement in the $x y$ direction is fixed; the top surface of the model is set as a free boundary without any constraint. The roadway is set to a rigid body without movement and deformation and is only used to observe the force of the granular body.

\subsection{Model Parameter Setting and Excavation Scheme Design.} According to the survey and statistics of the size of the rock block in the collapsed body, all the block sizes of the surrounding rock collapsed body of the roadway are mainly concentrated in $100-200 \mathrm{~mm}$. The particle size was set to $100 \mathrm{~mm}$ and $200 \mathrm{~mm}$ and between 100 and $200 \mathrm{~mm}$. According to the above research conclusions and the results of laboratory physical mechanics experiments, particulate materials are assigned. By changing the particle size, number, natural repose angle, and excavation position, 15 groups of different numerical simulations were carried out. The specific parameters are shown in Table 2. Two excavation positions are simulated and they are selected in the lower left and middle lower parts of the roadway. In order to facilitate the observation of the occurrence state of the granular body in the roadway after excavation, according to the rescue space that the human body can pass, the rescue roadway is designed to be between 0.5 and $1 \mathrm{~m}$, and the excavation area size is $1 \mathrm{~m} \times 1 \mathrm{~m}$ and excavated 6 times. Excavation area is $1 \mathrm{~m} \times 0.5 \mathrm{~m}$ and $0.5 \mathrm{~m} \times 1 \mathrm{~m}$ and excavation is 12 times, when the total excavation area reached $6 \mathrm{~m}^{2}$, the occurrence state of the excavated excavation is observed and the movement law of the particles is analyzed.

\subsection{The Formation Process and Force Characteristics of the} Collapsed Body. All the particles are directly generated in the upper part of the roadway model, and gravity is applied to the particles to make them fall freely. During the falling process, the particles collide with particles and with sidewalls, and collision disappeared until a stable state is reached (Figure 5).

In order to more vividly illustrate the particle movement process and be consistent with the field roof, a multicolor layering is used. During the initial process of filling the coal granular body with the roadway, the particles continue to fall on the upper part, for which the coal particles are continuously compacted. When completely collapsed, the coal particles are completely filled with the roadway. The process of falling into the roadway is consistent with the field.

According to the horizontal stress cloud picture and the vertical stress cloud picture of Figure 6, the horizontal stress increases with the increase of the coal granular body depth, and the horizontal stress extreme value appears in the left and right symmetrical position and the nonlowest part; the horizontal force extreme value appears on the right side of the bottom plate. Stress of other areas is more stable. The vertical stress gradually increases with the increase of the coal granular body depth, but the value on the side wall is small because the friction with the side wall is not considered; the vertical high stress area is concentrated on the bottom plate, and the maximum value is located on the right floor. It is shown that the maximum lateral compressive stress is near the bottom of the roadway. Because the granular particles are not evenly distributed, the maximum stress of the floor of the roadway is not always at the center of the floor, but there is a certain deviation, and the minimum stress is always close to the roof.

\subsection{Analysis of the Occurrence of Excavation of Surrounding} Rock Collapsed Body. According to the occurrence of the free-falling body, the left lower part and the middle part are excavated by $1 \mathrm{~m} \times 1 \mathrm{~m}$. The balance of the original force is broken by the excavation, and the excavation space is quickly filled by the surrounding granular particles. The excavation space is selected by the red frame, and the particle distribution of the filling space after excavation can be obtained. During the excavation process in the lower left part, the specific gravity of the coal particles with a particle size of $0.1 \mathrm{~m}$ is in the order of the first layer $>$ the second layer $>$ the third layer $>$ the fourth layer. The specific gravity of the coal particles with a particle size of $0.1 \mathrm{~m}-0.2 \mathrm{~m}$ is in the order of the second layer $>$ the first layer $>$ the third layer $>$ the fourth layer. The specific gravity order of $0.2 \mathrm{~m}$ coal particles is in the first layer $>$ the second layer $>$ the third layer $\approx$ the fourth layer; during the middle and lower excavation process, the specific gravity of the coal particles with a particle size of $0.1 \mathrm{~m}$ is in the order of the first layer $>$ the second layer $>$ the third layer $>$ the fourth layer. The particle size of $0.1 \mathrm{~m}-0.2 \mathrm{~m}$ coal particles is in the order of the first layer $\approx$ the second layer $>$ the third layer $>$ the fourth layer, and the specific gravity of particle size of $0.2 \mathrm{~m}$ is in the order of the first layer $\approx$ the second layer $>$ the third layer $>$ and the fourth layer. It indicates that in the left lower and middle lower excavation, the vertical filling speed is more than the horizontal speed. The vertical direction is the main part of the filling, and the horizontal direction is the secondary part of filling; the phenomenon of the different layers with different particle sizes filling is obvious (Figures 7 and 8 ).

According to the results of the excavation at the lower left part, the inclined surface formed by the granular body after excavation is negatively correlated with the particle size, and the smaller the particle size, the larger the inclination angle of the stable surface formed after excavation. After the middle and lower part of the excavation, two 
TABLE 2: Mechanical property of model.

\begin{tabular}{|c|c|c|c|c|c|c|c|c|}
\hline Number & $\begin{array}{c}\text { Material } \\
\text { properties }\end{array}$ & $\begin{array}{l}\text { Particle } \\
\text { quantity }\end{array}$ & $\begin{array}{c}\text { Particle } \\
\text { size }(\mathrm{mm})\end{array}$ & $\begin{array}{c}\text { Density } \\
\left(\mathrm{kg} \cdot \mathrm{m}^{-3}\right)\end{array}$ & $\begin{array}{c}\text { Tensile } \\
\text { strength }(\mathrm{MPa})\end{array}$ & $\begin{array}{l}\text { Local damping } \\
\text { coefficient }\end{array}$ & $\begin{array}{l}\text { Excavation } \\
\text { position }\end{array}$ & $\begin{array}{c}\text { Natural repose } \\
\text { angle }\end{array}$ \\
\hline 1 & \multirow{15}{*}{ Coal } & 1458 & 100 & \multirow{15}{*}{1650} & \multirow{15}{*}{0.51} & \multirow{15}{*}{0.3} & Shear stress part & $16^{\circ}$ \\
\hline 2 & & 1458 & 100 & & & & Shear stress part & $26^{\circ}$ \\
\hline 3 & & 1458 & 100 & & & & Shear stress part & $36^{\circ}$ \\
\hline 4 & & 1458 & 100 & & & & Shear stress part & $46^{\circ}$ \\
\hline 5 & & 1458 & 100 & & & & Middle lower part & $46^{\circ}$ \\
\hline 6 & & 353 & 200 & & & & Shear stress part & $16^{\circ}$ \\
\hline 7 & & 353 & 200 & & & & Shear stress part & $26^{\circ}$ \\
\hline 8 & & 353 & 200 & & & & Shear stress part & $36^{\circ}$ \\
\hline 9 & & 353 & 200 & & & & Shear stress part & $46^{\circ}$ \\
\hline 10 & & 353 & 200 & & & & Middle lower part & $46^{\circ}$ \\
\hline 11 & & 742 & $100-200$ & & & & Shear stress part & $16^{\circ}$ \\
\hline 12 & & 742 & $100-200$ & & & & Shear stress part & $26^{\circ}$ \\
\hline 13 & & 742 & $100-200$ & & & & Shear stress part & $36^{\circ}$ \\
\hline 14 & & 742 & $100-200$ & & & & Shear stress part & $46^{\circ}$ \\
\hline 15 & & 742 & $100-200$ & & & & Middle lower part & $46^{\circ}$ \\
\hline
\end{tabular}

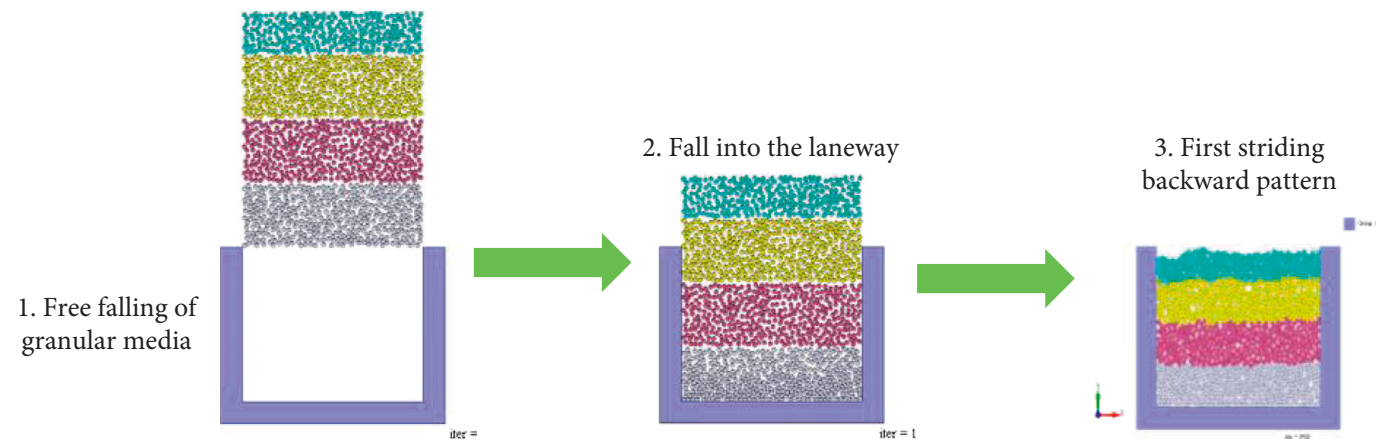

FIgURE 5: Particle formation process.

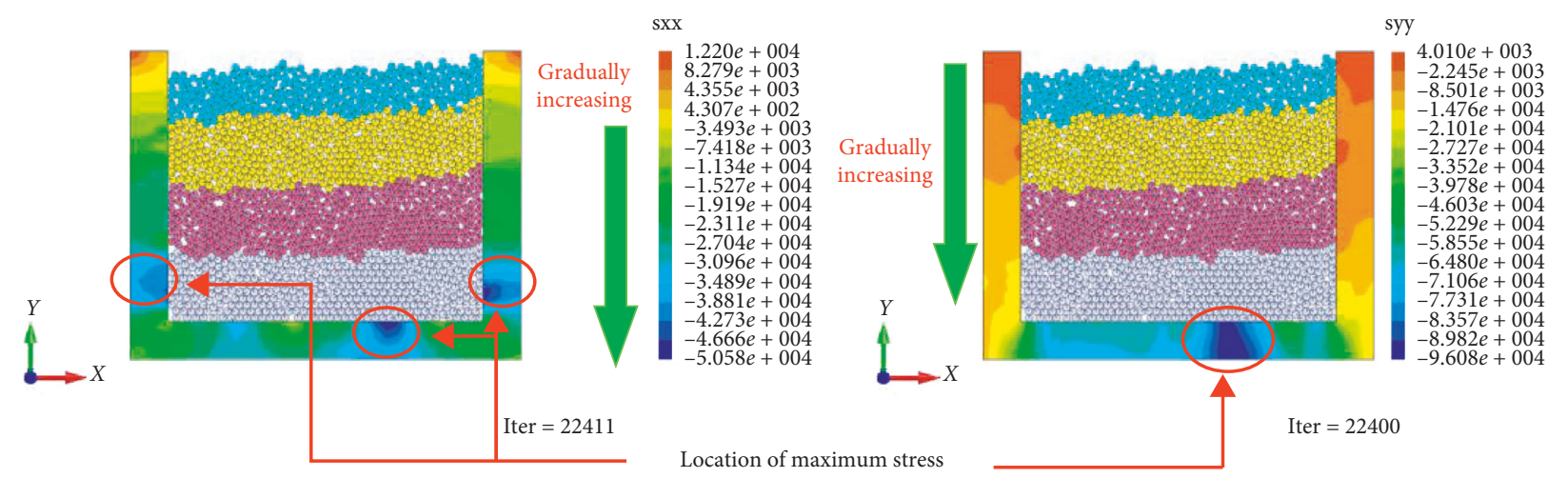

FIgure 6: Collapsed body stress cloud picture.

inclined faces are formed by the granular particles. With the increase of the particle size of the coal granular body, the angle of the slope is less obvious, but the overall trend of the slope is "V", and the left and right slopes are equal.

4.5. Influence of Excavation Shape and Volume on the Movement of Coal Granular Body. In order to study the effect of excavation shape on the filling of coal granular body and stable inclined surface, different particle sizes and the same excavation volume were adopted, and the excavation dimensions were $0.5 \mathrm{~m} \times 1 \mathrm{~m}$ and $1 \mathrm{~m} \times 0.5 \mathrm{~m}$.

According to the collapsed filling pattern of Figure 9, when the size of the excavation area is $1 \mathrm{~m} \times 0.5 \mathrm{~m}$ and $1 \mathrm{~m} \times$ $1 \mathrm{~m}$, it is mainly filled by the particles in the vertical direction, and the horizontal particles filling is supplemented; the size of the excavation area is $0.5 \mathrm{~m}$. When the size of the excavation area is $0.5 \mathrm{~m} \times 1 \mathrm{~m}$, it is mainly filled by the particles in the horizontal direction, and the vertical filling of the particles is supplemented. The comparison shows that 


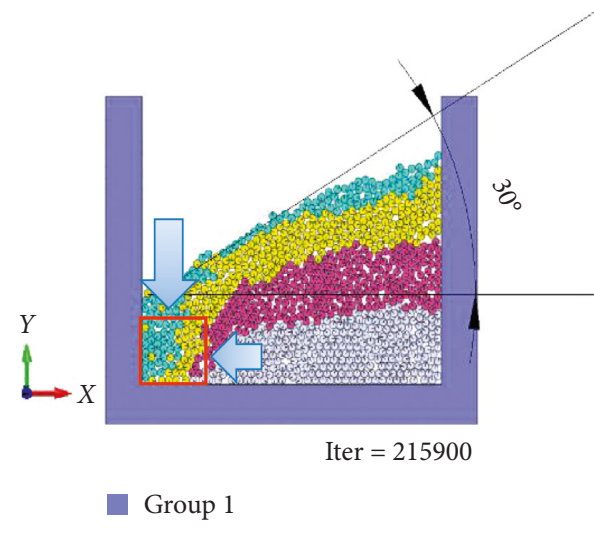

(a)

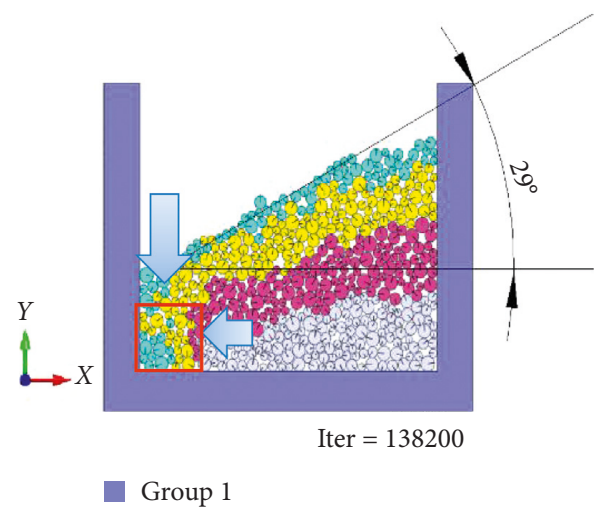

(b)

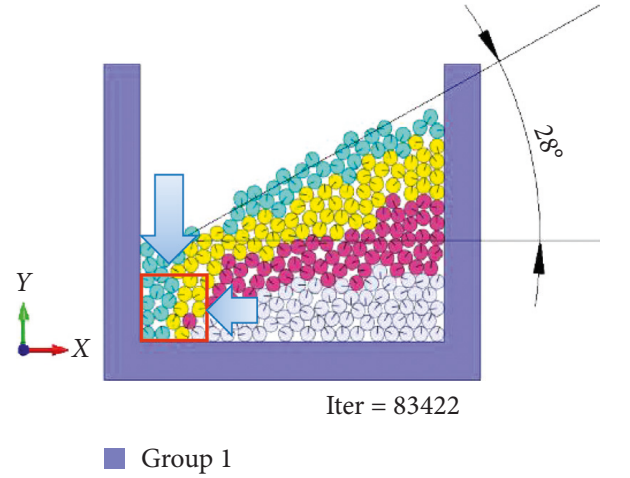

(c)

Figure 7: Collapsed process of excavation of the left lower part of coal particles with different particle sizes. (a) Coal particles of $0.1 \mathrm{~m}$ particle size. (b) Coal particles of 0.1-0.2 m particle size. (c) Coal particles of $0.2 \mathrm{~m}$ particle size.

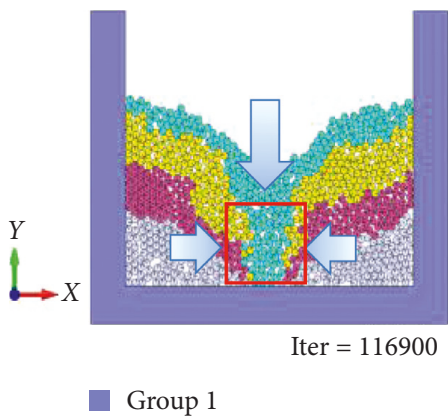

(a)

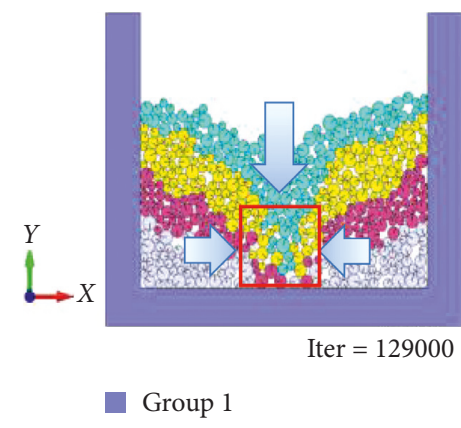

(b)

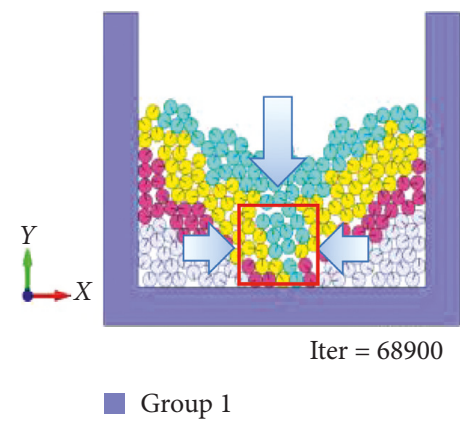

(c)

Figure 8: Collapsed process of excavation of the lower central lower part of coal particles with different particle sizes. (a) Coal particles of $0.1 \mathrm{~m}$ particle size. (b) Coal particles of 0.1-0.2 m particle size. (c) Coal particles of $0.2 \mathrm{~m}$ particle size.

the size of the longitudinal dimension determines the primary-secondary relationship of the flow direction of the particles. Under the same excavation area, the inclined surface angle formed by excavation $1 \mathrm{~m} \times 0.5 \mathrm{~m}$ is less than that of $0.5 \mathrm{~m} \times 1 \mathrm{~m}$, and the smaller the particle size, the larger the angular difference formed. When the excavation scales of the same particle size are the same, the inclination angle of the inclined surface becomes smaller, which is consistent with the excavation law of $1 \mathrm{~m} \times 1 \mathrm{~m}$ in the lower left part. When different excavation volume are compared, the inclination angle of the inclined surface is consistent with
$1 \mathrm{~m} \times 0.5 \mathrm{~m}$ and $1 \mathrm{~m} \times 1 \mathrm{~m}$. Compared with $0.5 \mathrm{~m} \times 1 \mathrm{~m}$ and $1 \mathrm{~m} \times 1 \mathrm{~m}$, the inclination angles of the inclined planes are inconsistent. The excavation width is independent of the angle of the inclined plane, and the excavation height is positively correlated with the slip angle.

4.6. Influence of Internal Friction Angle on the Occurrence of Granular Body. Under ideal conditions (no cohesion or neglect of cohesion), the internal friction angle is the elastic constant of the coal sample of the ideal granular body, and 


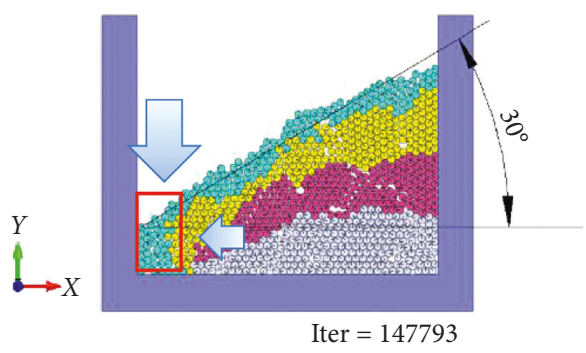

Group 1

(a)

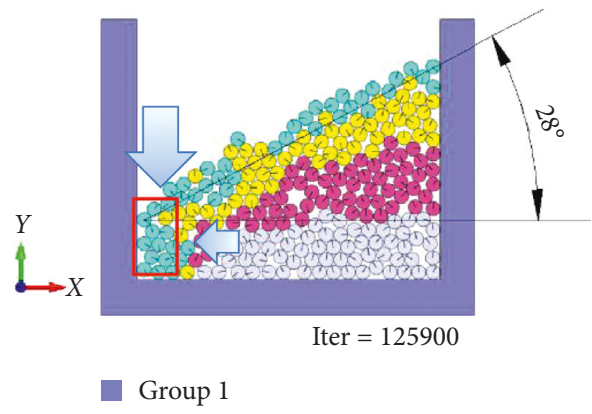

(c)

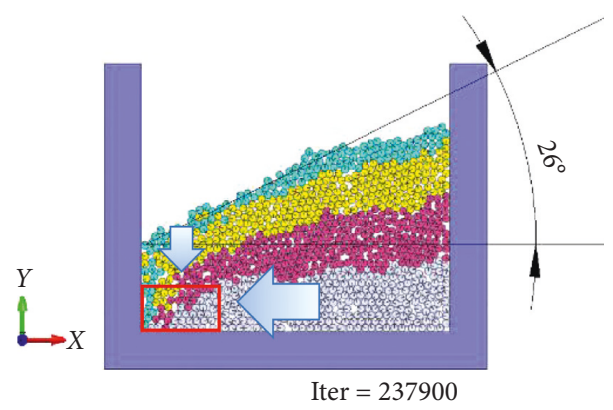

Group 1

(b)

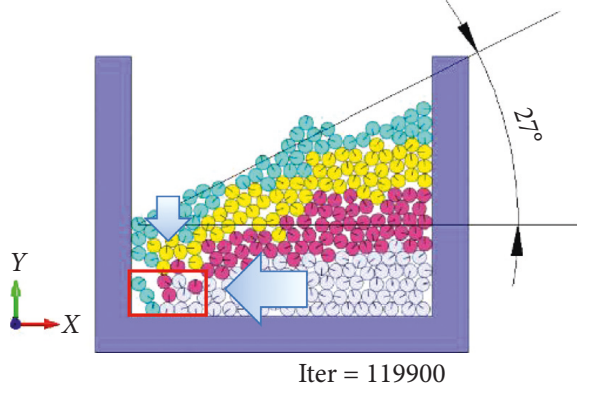

Group 1

(d)

FiguRE 9: Relationship between excavation shape and coal collapsed body. (a) $0.1 \mathrm{~m}$ particle size and $1 \mathrm{~m} \times 0.5 \mathrm{~m}$ excavation. (b) $0.1 \mathrm{~m}$ particle size and $0.5 \mathrm{~m} \times 1 \mathrm{~m}$ excavation. (c) $0.2 \mathrm{~m}$ particle size and $1 \mathrm{~m} \times 0.5 \mathrm{~m}$ excavation (d) $0.2 \mathrm{~m}$ particle size and $0.5 \mathrm{~m} \times 1 \mathrm{~m}$ excavation.

the natural repose angle is the angle formed by particles moving by weight. The numerical value is equal to the natural repose angle. Because the cohesive force of coal particles is very small, it can be neglected. The natural repose angle of coal particles with different particle sizes can be obtained through experiments. The natural repose angle is used to calculate the dip angle of the slip surface, and the influence of the natural repose angle on the slip of coal particles is analyzed.

Figure 10 shows the inclined surface formed after excavation of the left lower part $1 \mathrm{~m} \times 1 \mathrm{~m}$ when the natural repose angle is $16^{\circ}$ and $26^{\circ}$. In Figure 10(a), when the natural repose angle is $16^{\circ}$, the inclined surface inclination angle is $26^{\circ}$; when the natural repose angle is $26^{\circ}$, the inclined surface inclination angle is $28^{\circ}$; when the natural repose angle is $36^{\circ}$, the inclined surface inclination angle is $30^{\circ}$. As the natural repose angle increases, the inclination of the inclined surface also increases. It can be seen from the proportion of the particle-filled excavation space that the vertical filling amount is larger than that of the horizontal direction.

\section{Analysis of the Movement Track of the Surrounding Rock Excavation}

5.1. Variation of Displacement Field of Excavation of Surrounding Rock Mass. Much excavation is carried out in the surrounding rock of the roadway. The movement displacement of the particles can be drawn by monitoring the tracking of the upper particles. In the figure, $Y$ is the height of the monitoring point, and $X$ is the horizontal displacement of the monitoring point. Through the numerical simulation experiment on the excavation of the bulk, a large amount of excavation particle movement data is obtained.

By comparing Figures 11(a), 11(b), and 11(c), it can be seen that the particle trajectories of different particle sizes are similar, and all the particle movements are obviously directed to the excavation space. Extrusion force, boundary friction force, and distance lead to particles not at all pointing to excavation space. During the initial excavation process, the particle motion is perpendicular to the space above the excavation space, and as the horizontal position increases, the moving distance becomes smaller and smaller, indicating that the farther away from the excavation space, the weaker the influence on the particle movement. As the excavation continues, the particle movement at the monitoring point is still inversely related to the excavation distance. For the single monitoring point above the nonvertical excavation, as the number of excavation increases, the moving distance becomes longer and the pointing becomes more and more obvious. In other words, the closer to the excavation space is, the bigger effect on the particle movement is. Because the movement curve is obvious zoning, the curve is divided according to the excavation moving distance. The upper part is the dense area and the lower part is the loose area. The excavation process of the dense area has little effect on the movement, while movement is more greatly impacted by the loose area. It can be clearly seen from the added lateral auxiliary line that as the 


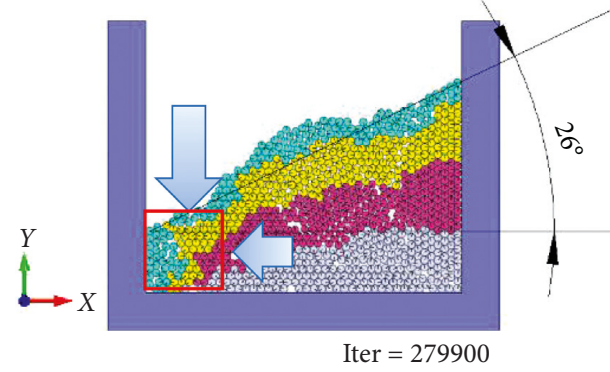

Group 1

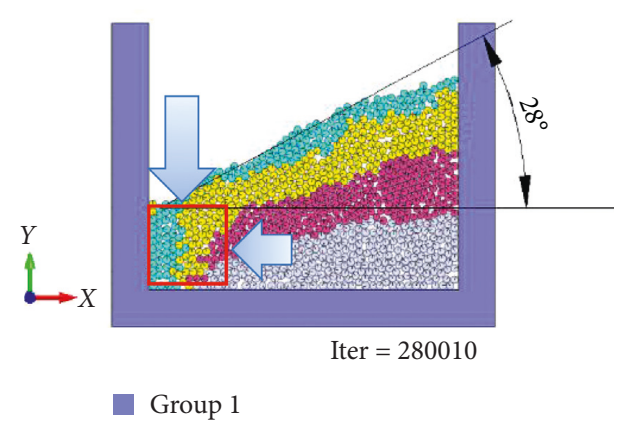

(b)

Figure 10: $0.1 \mathrm{~m}$ coal with different natural repose angle and excavation left lower part $1 \mathrm{~m} \times 1 \mathrm{~m}$. (a) Natural repose angle is $16^{\circ}$. (b) Natural repose angle is $26^{\circ}$.

particle size increases, the auxiliary line appears to move downwards. The moving speed is limited by the particle size. As the particle size increases, the limit is decreased. The bigger the particle size, the uniform the particle size movement. It is also known that the distance of the particles becomes short as the particle diameter increases compared with the total moving path.

Comparing the displacement maps of the same excavation area in the lower left part (Figures 11(c) and 11(d)), the excavation area is always $0.5 \mathrm{~m} \times 1 \mathrm{~m}$, and the excavation area is closer to the excavation space than the $1 \mathrm{~m} \times 0.5 \mathrm{~m}$ particle retention position, and the moving distance is farther. Therefore, from the moving distance, the same volume, $1 \mathrm{~m} \times 0.5 \mathrm{~m}$ excavation should be preferred to choose. In the $1 \mathrm{~m} \times 0.5 \mathrm{~m}$ excavation method, particles point to the full excavation space, and the particles move to $1.5 \mathrm{~m}$ and appear vertical drop. In the $0.5 \mathrm{~m} \times 1 \mathrm{~m}$ excavation method, particles point to the semiexcavation space. When the horizontal ordinate enters $0.5 \mathrm{~m}$ and the ordinate reaches $1.5 \mathrm{~m}$, the particles fall vertically. The pointing regularity of $1 \mathrm{~m} \times 0.5 \mathrm{~m}$ excavation is more obvious than $0.5 \mathrm{~m} \times 1 \mathrm{~m}$.

Comparing the displacement pictures of the same excavation area in the middle and lower parts (Figures 11(e) and 11(f)), both sides of the excavation area point to the excavation space and have obvious symmetry. When the excavation area is $1 \mathrm{~m} \times 0.5 \mathrm{~m}$, the particle retention position is closer to the excavation space and moves farther. Comparing the different excavation positions of the same excavation shape (Figures 11(c) and 11(e)), the influence range of the central excavation is large and balanced, and the influence range of side wall excavation is small and unbalanced, so the overall support resistance of the central excavation is greater. The side support excavation has large local support resistance. When the external resistance is only gravity and small, the comprehensive support is timeconsuming and laborious. The local support should be selected, and the side wall excavation is better.

Compared with the excavation space area of $1 \mathrm{~m} \times 1 \mathrm{~m}$, the movement distance and mode of particles in the excavation areas of $0.5 \mathrm{~m} \times 1 \mathrm{~m}$ and $1 \mathrm{~m} \times 0.5 \mathrm{~m}$ are more stable. Therefore, when the same excavation amount is used, multiple small volume excavations should be selected and gradually form a generous volume.
5.2. Change of Velocity Field of Excavation of Surrounding Rock Mass. Each point in the excavation process is monitored and time parameters are given to obtain a velocity cloud picture in the vertical direction of the granular body movement. In the following, the representative movement processes caused by left lower $1 \mathrm{~m} \times 1 \mathrm{~m}$ and middle lower part $1 \mathrm{~m} \times 1 \mathrm{~m}$ excavation are studied.

The trend of the velocity field during the excavation of coal particles is shown in Figure 12. In Figure 12(a), the velocity field shows obvious zoning characteristics. There is a triangular inert zone on the right side, and the adjacent position is the motion zone. The interface between the zone and the inert zone is a slip surface. The velocity field gradually increases from right to left, and a high-speed zone appears above the excavation face. In order to analyze the variation characteristics of the velocity field of the collapse process, the variation law of the partial collapse velocity field is analyzed. With the fall of the collapsed body, the collapsed body falling into the bottom plate becomes a low-speed particle, which is stable. The high-speed zone is moving up. The proportion of low-speed particles is increasing, indicating that it is gradually stabilizing. From the distribution of the velocity field, the proportion of particles in the collapsed excavation area can also be obtained. Although the filling path in the horizontal direction is short, the filling speed is slow. Although the vertical direction is long, the speed is fast. In the collapsed excavation, the particles in the zone are predominantly in the vertical direction. When excavating in the middle and lower part, the law is basically similar to the law of excavation in the lower left part, but a symmetrical velocity field is formed in the central excavation. There is a "nuclear" type feature, the core speed is the fastest, and the medium core speed is faster. But the arc boundary line is obviously formed, which is next to the core. The boundary between the middle core and the outer core is a slip surface, and the area of the outer core is a stable area.

5.3. Study of Slip Surface Changes Based on Velocity Field. The particles with the particle size of $0.1 \mathrm{~m}, 0.1-0.2 \mathrm{~m}$, and $0.2 \mathrm{~m}$ are excavated separately. By comparing the coordinates before and after the excavation of the particles, the particles with little or no movement are found, and the 


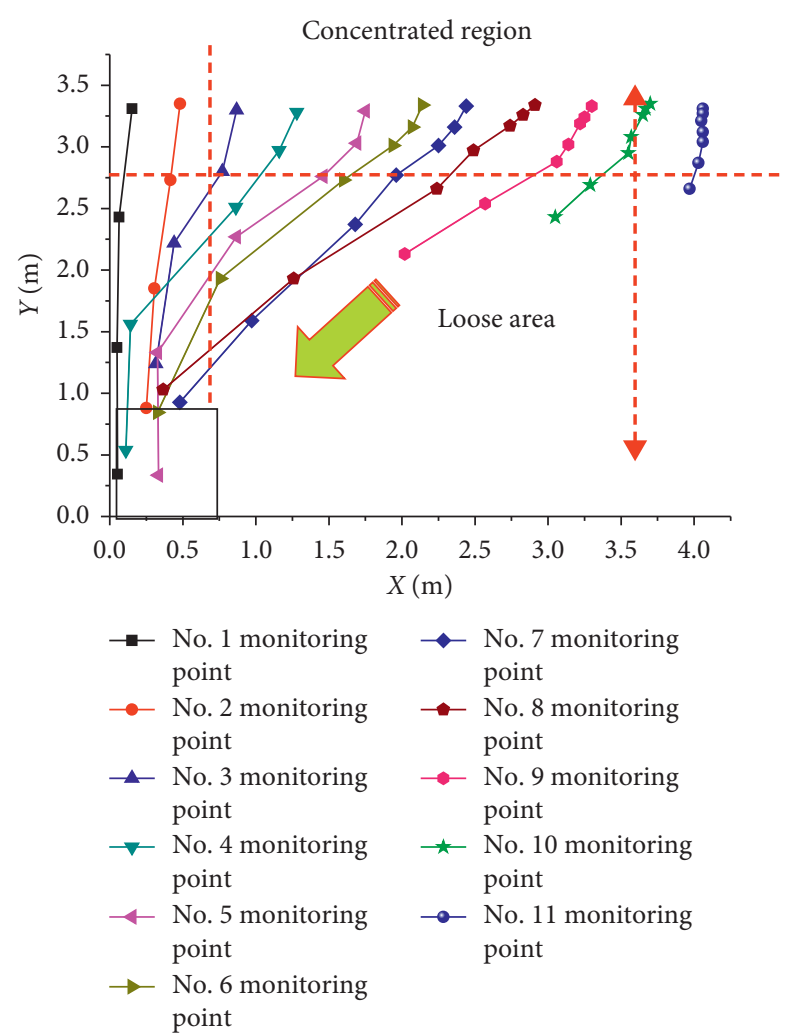

(a)

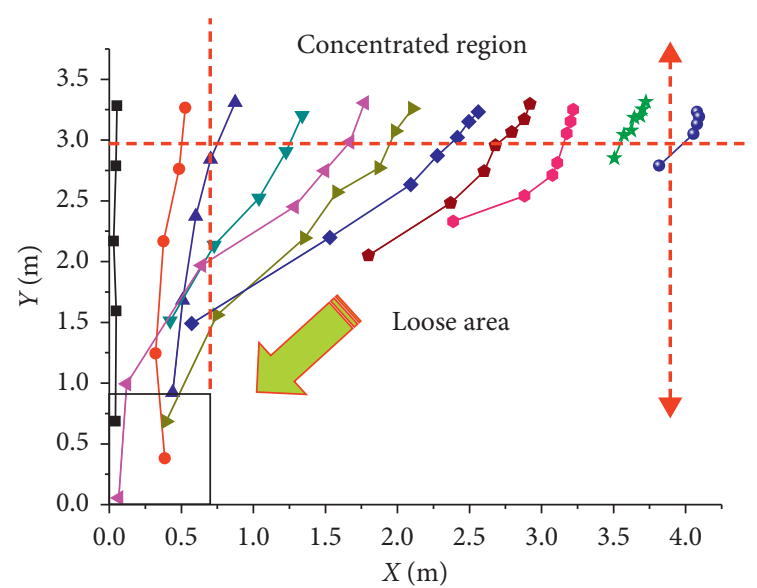

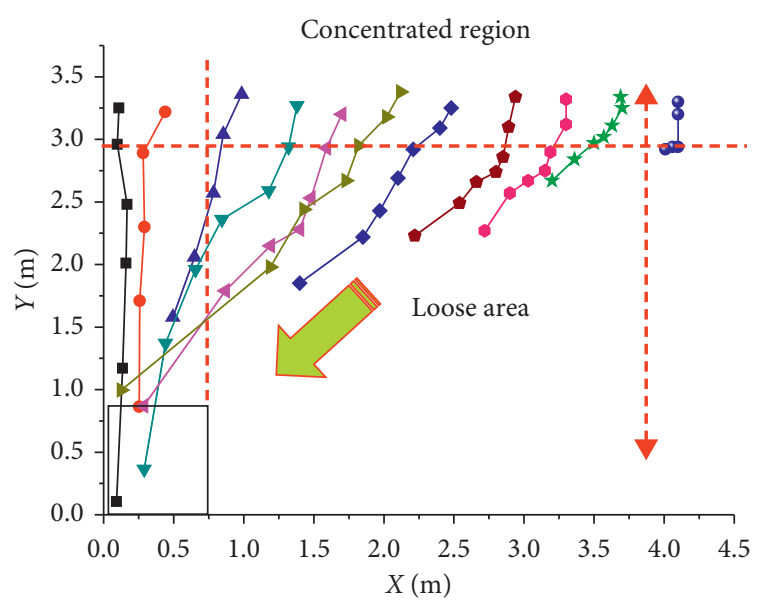

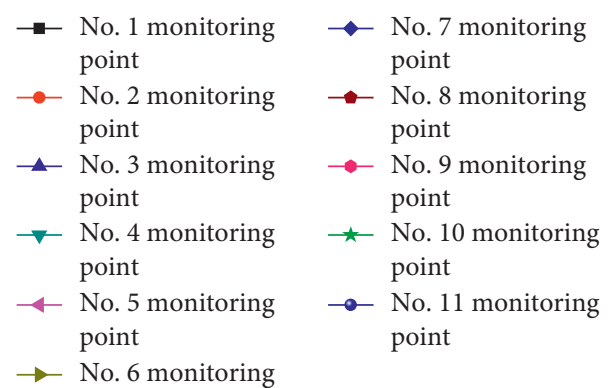
point

(b)

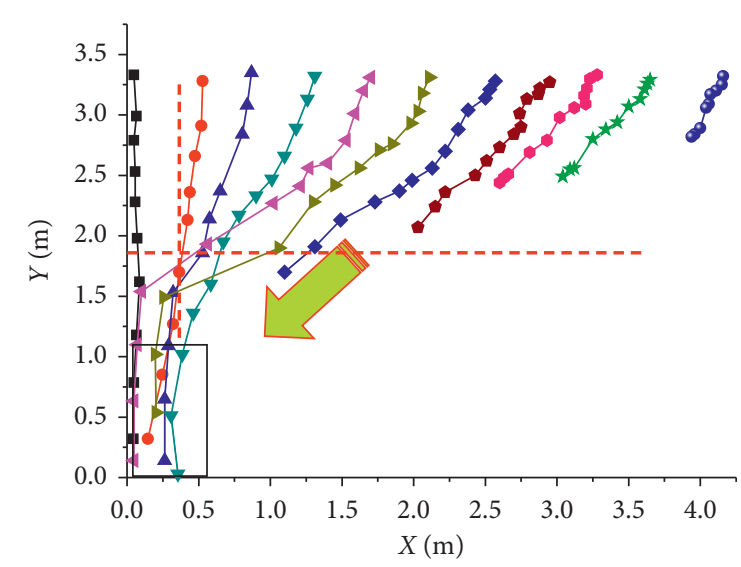

$\rightarrow$ - No. 1 monitoring point

$\neg$ No. 7 monitoring point

$\multimap$ No. 2 monitoring $\multimap$ No. 8 monitoring point point

$\multimap$ No. 3 monitoring $\multimap$ No. 9 monitoring point point

$\neg$ No. 4 monitoring point

^ No. 10 monitoring point

$\longleftarrow$ No. 5 monitoring point

$\multimap$ No. 11 monitoring point

$\rightarrow$ No. 6 monitoring point

(c)

FIgUre 11: Continued. 


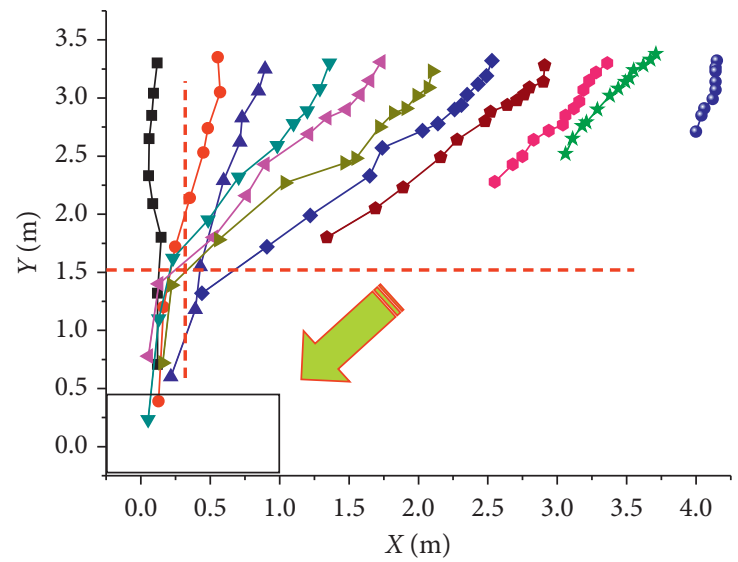

\begin{tabular}{|c|c|c|c|}
\hline$\rightarrow-$ & $\begin{array}{l}\text { No. } 1 \text { monitoring } \\
\text { point }\end{array}$ & $\bullet$ & $\begin{array}{l}\text { No. } 7 \text { monitoring } \\
\text { point }\end{array}$ \\
\hline$\rightarrow$ & $\begin{array}{l}\text { No. } 2 \text { monitoring } \\
\text { point }\end{array}$ & $\rightarrow$ & $\begin{array}{l}\text { No. } 8 \text { monitoring } \\
\text { point }\end{array}$ \\
\hline-1 & $\begin{array}{l}\text { No. } 3 \text { monitoring } \\
\text { point }\end{array}$ & & $\begin{array}{l}\text { No. } 9 \text { monitoring } \\
\text { point }\end{array}$ \\
\hline & $\begin{array}{l}\text { No. } 4 \text { monitoring } \\
\text { point }\end{array}$ & $\rightarrow$ & $\begin{array}{l}\text { No. } 10 \text { monitoring } \\
\text { point }\end{array}$ \\
\hline 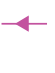 & $\begin{array}{l}\text { No. } 5 \text { monitoring } \\
\text { point }\end{array}$ & $\rightarrow$ & $\begin{array}{l}\text { No. } 11 \text { monitoring } \\
\text { point }\end{array}$ \\
\hline
\end{tabular}

$\rightarrow$ No. 6 monitoring point

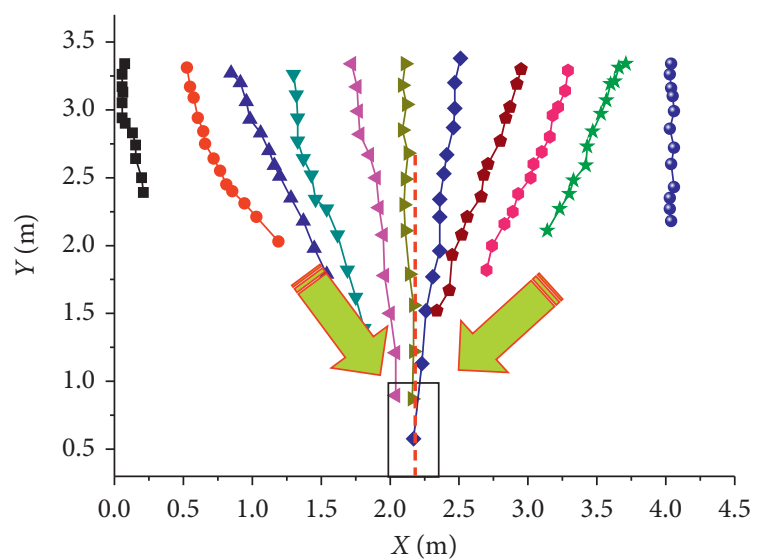

- No. 1 monitoring point

$\_$No. 7 monitoring point

$\multimap$ No. 2 monitoring $\_$No. 8 monitoring point point

$\multimap$ No. 3 monitoring $\multimap$ No.9 monitoring point point

$\neg$ No. 4 monitoring $\quad$ ॠ No. 10 monitoring point point

$\multimap$ No. 5 monitoring $\multimap$ No. 11 monitoring point point

$\rightarrow$ No. 6 monitoring point

(e)

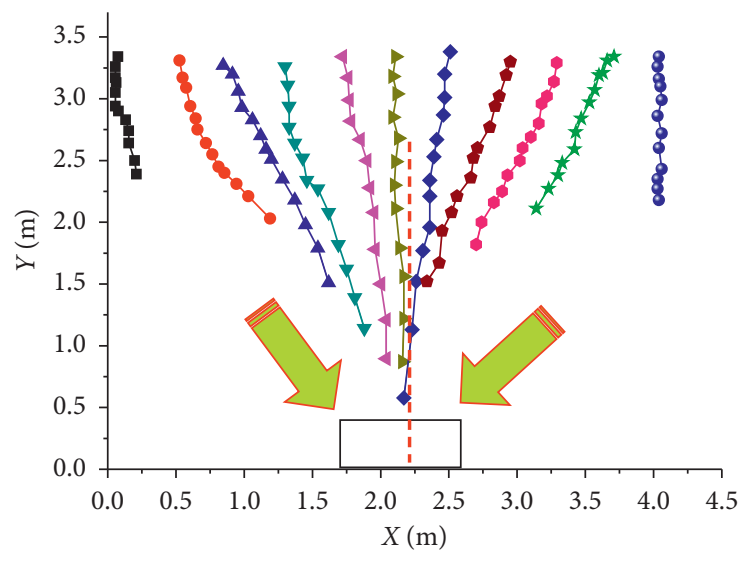

\begin{tabular}{|c|c|c|c|}
\hline$=$ & $\begin{array}{l}\text { No. } 1 \text { monitoring } \\
\text { point }\end{array}$ & $\bullet$ & $\begin{array}{l}\text { No. } 7 \text { monitoring } \\
\text { point }\end{array}$ \\
\hline$\bullet$ & $\begin{array}{l}\text { No. } 2 \text { monitoring } \\
\text { point }\end{array}$ & $\rightarrow$ & $\begin{array}{l}\text { No. } 8 \text { monitoring } \\
\text { point }\end{array}$ \\
\hline 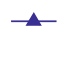 & $\begin{array}{l}\text { No. } 3 \text { monitoring } \\
\text { point }\end{array}$ & $\rightarrow$ & $\begin{array}{l}\text { No. } 9 \text { monitoring } \\
\text { point }\end{array}$ \\
\hline$\rightarrow$ & $\begin{array}{l}\text { No. } 4 \text { monitoring } \\
\text { point }\end{array}$ & - & $\begin{array}{l}\text { No. } 10 \text { monitoring } \\
\text { point }\end{array}$ \\
\hline 4 & $\begin{array}{l}\text { No. } 5 \text { monitoring } \\
\text { point }\end{array}$ & $\rightarrow$ & $\begin{array}{l}\text { No. } 11 \text { monitoring } \\
\text { point }\end{array}$ \\
\hline$\rightarrow$ & $\begin{array}{l}\text { No. } 6 \text { monitoring } \\
\text { point }\end{array}$ & & \\
\hline
\end{tabular}

(g)

Figure 11: Moving track of coal particle excavation. (a) $0.1 \mathrm{~m}$ particle size. (b) $0.2 \mathrm{~m}$ particle size. (c) $0.1-0.2 \mathrm{~m}$ particle size. (d) $1 \mathrm{~m} \times 0.5 \mathrm{~m}$ excavation. (e) $0.5 \mathrm{~m} \times 1 \mathrm{~m}$ excavation. (f) $1 \mathrm{~m} \times 0.5 \mathrm{~m}$ excavation. $(\mathrm{g}) 0.5 \mathrm{~m} \times 1 \mathrm{~m}$ excavation. 


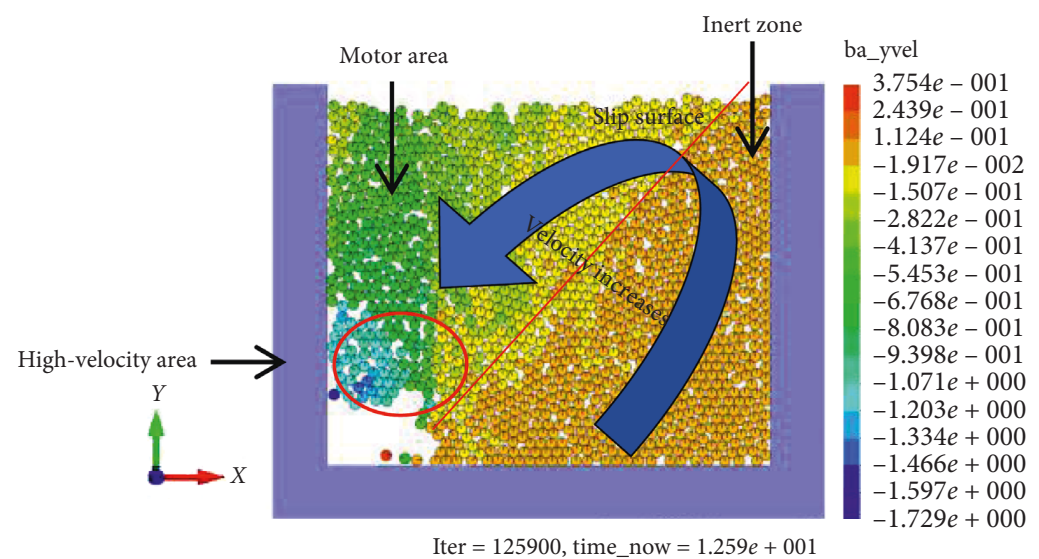

(a)

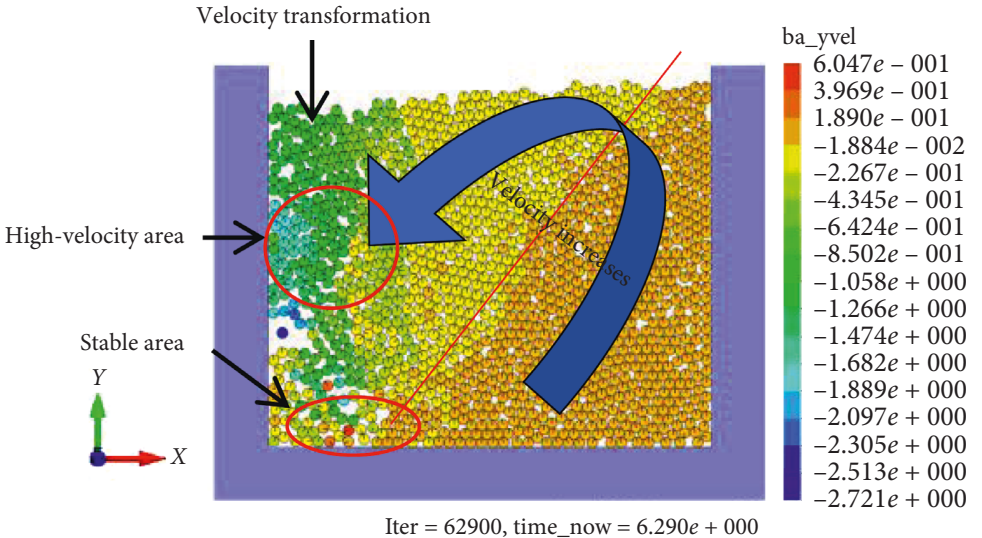

(b)

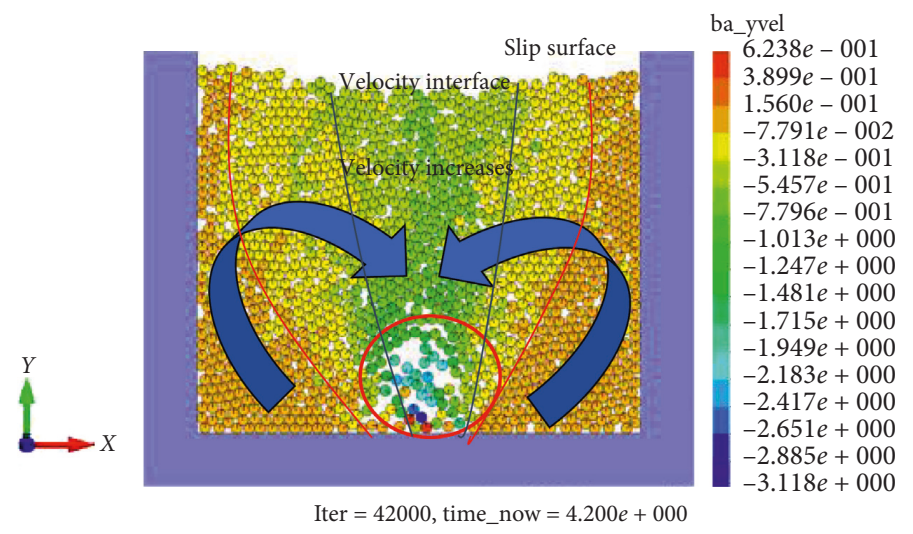

(c)

Figure 12: Change trend of velocity field of coal particle excavation. (a) Initial collapse of the lower left part of $0.1 \mathrm{~m}$ coal particles. (b) The collapsing process of the lower left part of $0.1 \mathrm{~m}$ coal particles. (c) The collapsing process of the lower middle part of $0.1 \mathrm{~m}$ coal particles.

particles on the boundary are used as the slip surface. The particle coordinates on the boundary are used to draw the slip surface. The slip surface of the left lower granular body excavation is shown in Figure 13.

The particles in the lower left part of the figure are excavated particles, and the particles stacked on the right side of the triangle are particles with relatively little or no movement, and the slip surface of the excavation of the granular body is constituted by the particles on the oblique side of the triangle. The slip surface angle obtained by a large number of excavations is measured. Although the inclination angle of the slip surface does not always reach the maximum due to the position and the gap of the granular particles, the maximum inclination surface angle of the different coal granular particle sizes is all $52^{\circ}$. It can be seen that when the natural repose angle is the same, the particle size of the granular body has no influence on the inclination angle of the slip surface. According to formula (11), the angle of the slip surface is calculated to be $63^{\circ}$, and the value obtained by the simulation is slightly smaller. It 


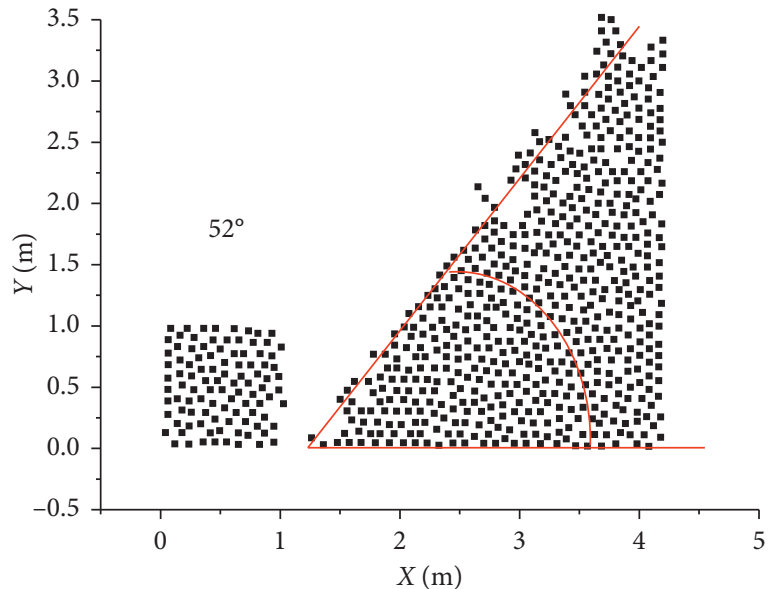

- Granular particles

(a)

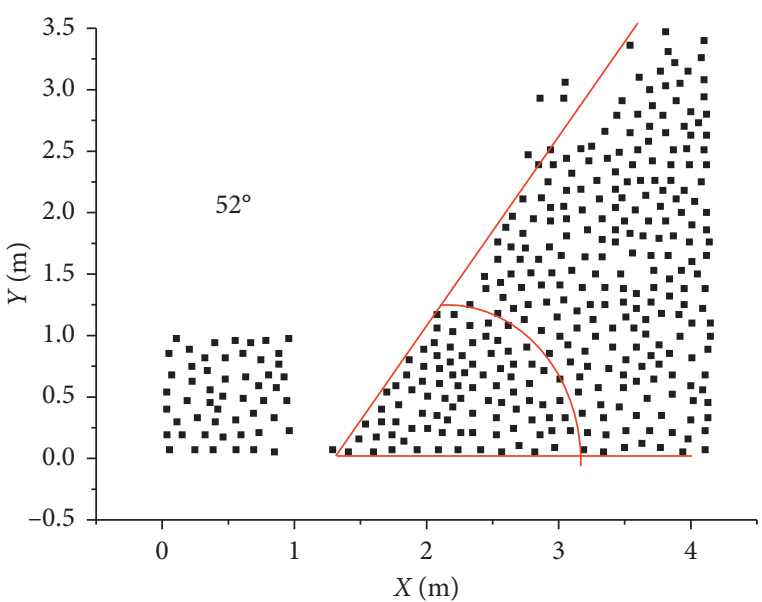

- Granular particles

(b)

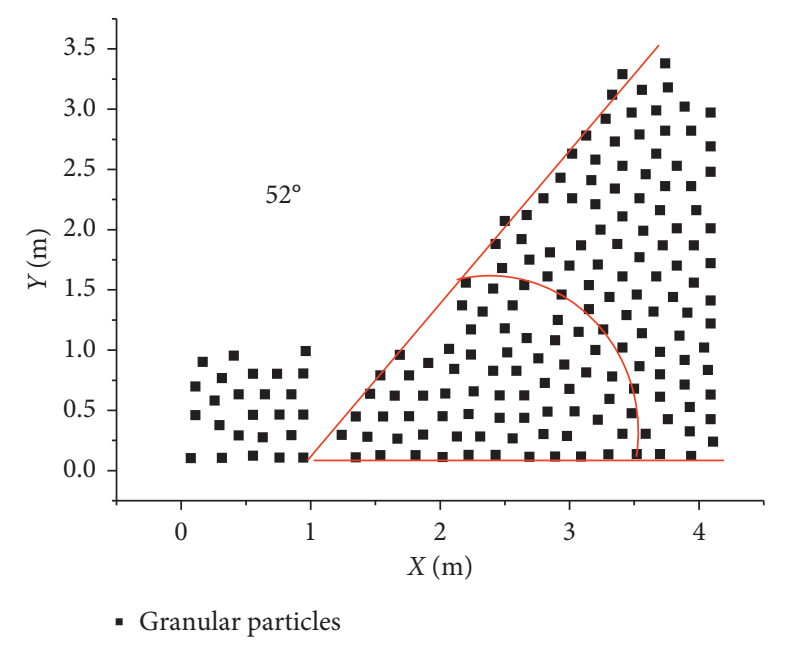

(c)

Figure 13: The relationship between the particle size and the slip surface. (a) $0.1 \mathrm{~m}$ particle size. (b) $0.1 \mathrm{~m}-0.2 \mathrm{~m}$ particle size. (c) $0.2 \mathrm{~m}$ particle size.

can be seen that in the excavation of the particles on the moving surface, the particles present in the upper part have a certain influence on the slip surface. The force is not considered in the theoretical formula, which results in a deviation of the result.

5.4. Relationship between Natural Repose Angle and Slip Surface. The natural repose angle is the inclination angle of a fracture surface. To explore the relationship between the slip surface of the coal granular body particle and the natural repose angle, the $1 \mathrm{~m} \times 1 \mathrm{~m}$ excavation experiment of the left lower part of the coal granular body at $46^{\circ}, 36^{\circ}, 26^{\circ}$, and $16^{\circ}$ is carried out. The result is shown in Figure 14.

It can be seen from the figure that when the natural repose angle of the coal granular body changes from large to small, the slip surface also shows a trend from large to small, and there are two linear relationships: when the natural repose angle is $46^{\circ}$, the excavation slip surface The angle is $56^{\circ}$; when the natural repose angle is $36^{\circ}$, the excavation slip surface angle is $52^{\circ}$; the natural repose angle is $26^{\circ}$, and the excavation slip surface angle is $48^{\circ}$; the natural repose angle is $16^{\circ}$, and the excavation slip surface angle is $44^{\circ}$. The natural repose angle decreasing by $10^{\circ}$ and the slip surface decreasing by $4^{\circ}$ are obtained by successive differences.

In Section 3.2, the dip angle of the slip surface of the roadside bulk is deduced by statics theory, and the relationship between the internal friction angle and the dip angle of slip surface is obtained. When the emergency rescue runnel is excavated in the bulk, the bulk solid first falls in the vertical direction, and then the sliding phenomenon occurs in the upper and inclined areas. The trajectories, velocities, and accelerations of the particles can be calculated. That is to say, the excavation roadway-particle movement-slip surface stability is a dynamic process. The movement of particles will "activate" neighboring particles. Particles will collide with other particles when moving at certain acceleration. It will promote further movement of the particles. This evolutionary effect eventually leads to the numerical calculation (dynamic) of the slip surface angle and is less than the theoretical calculation of the slip surface angle (static). 


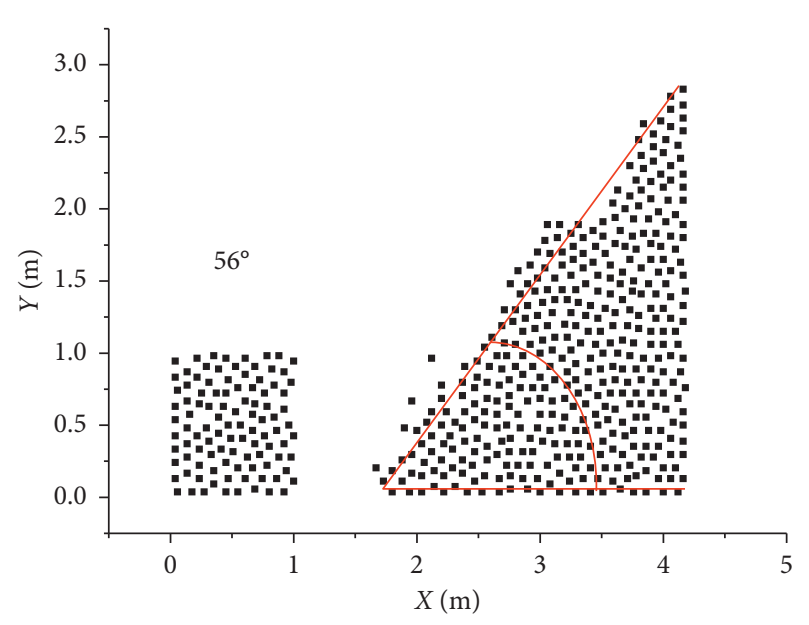

- Granular particles

(a)

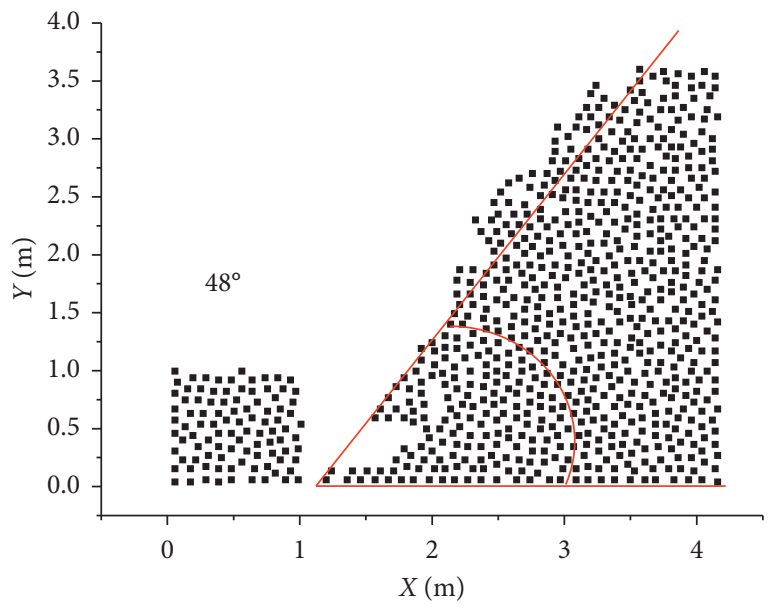

- Granular particles

(c)

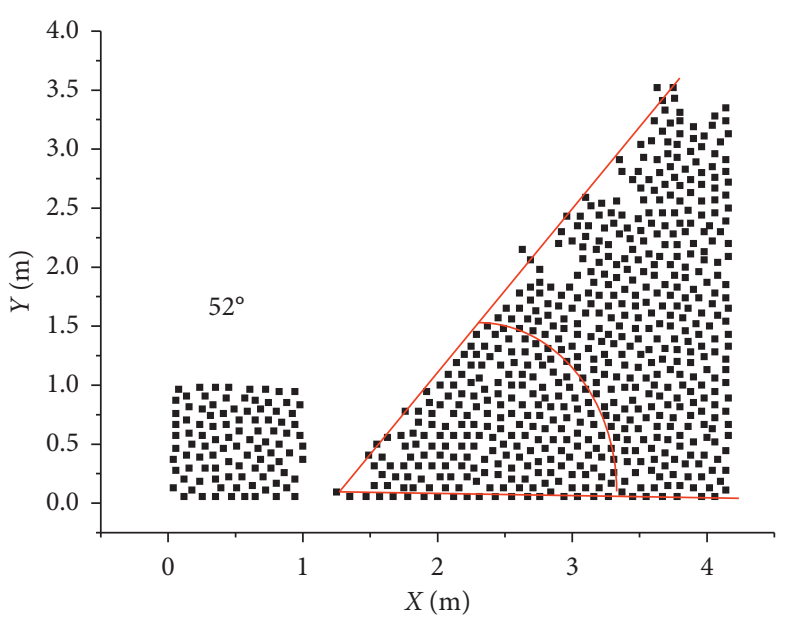

- Granular particles

(b)

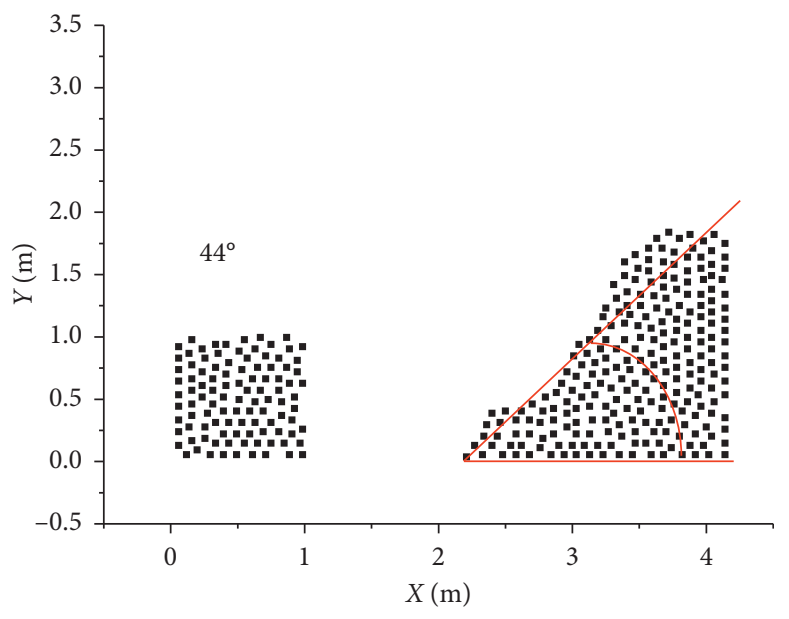

- Granular particles

(d)

Figure 14: The relationship between the natural repose angle and the slip surface. (a) The $46^{\circ}$ natural repose angle. (b) The $36^{\circ}$ natural repose angle. (c) The $26^{\circ}$ natural repose angle. (d) The $16^{\circ}$ natural repose angle.

\section{Conclusion}

In order to study the mechanical characteristics of the roadway excavation process, the field study of the roadway collapsed body was carried out. The lateral pressure coefficient and the slip angle of the slip surface were theoretically derived. The collapsing simulation experiment of coal granular body and numerical simulation experiment of coal granular body excavation were carried out. The following conclusions were obtained:

(1) The surrounding rock collapsed body can be approximately spherical in shape, the block in the surrounding rock collapsed body is compacted by its own weight, and the side wall of the roadway only plays a limiting role, but has no supporting reaction force.
(2) Both horizontal stress and vertical stress increase with the increase of coal granular body depth; vertical high stress regions are concentrated in the floor.

(3) When excavating the lower left part and the middle part, the vertical direction of the filling is main, and the horizontal direction of the filling is secondary. The stratification of the filling area of different particle sizes is obvious. The inclined surface formed by the granular body after excavation has a negative correlation with the particle size.

(4) The primary-secondary relationship of the flow direction of the particles is determined by the size of the longitudinal dimension. The excavation width is independent of the inclination angle of the inclined surface, and the excavation height is positively correlated with the slip angle. As the natural repose 
angle increases, the inclination angle of the inclined surface also increases.

(5) The movement of all the particles is obviously directed to the excavation space. The farther away from the excavation space, the weaker the influence on the movement of the particles. As the particle size increases, the boundary of the movement is lower and lower; when the excavation volume is same, multiple small volume excavations should be selected.

(6) The partitioning characteristics of velocity field are obvious. With the fall of the collapsed body, the collapsed body contacting the floor becomes a lowspeed particle, which is in a stable state, and the highspeed area appears to move up. Central excavation forms a "nuclear" type of feature.

(7) The maximum inclination angles of the coal granular body slip surface of different particle sizes are all $52^{\circ}$, and the particle size of the granular body is independent of the inclination angle of the slip surface. The natural repose angle is reduced by $10^{\circ}$, and the slip surface is decreased by $4^{\circ}$.

\section{Data Availability}

The data used to support the findings of this study are available from the corresponding author upon request.

\section{Conflicts of Interest}

The authors declare that they have no conflicts of interest.

\section{Acknowledgments}

This research was supported by the National Natural Science Foundation of China (51674107, 51574115, 51774121, and 51604100). The authors would like to thank all members for their help with the fieldwork in Heilongjiang Ground Pressure \& Gas Control in Deep Mining Key Lab (GPGC).

\section{References}

[1] H. Chuanbo, G. Zhang, G. Hu et al., "Prospect of study on tunnel collapse during rescue following disaster in coal mines," Journal of Heilongjiang Institute of Science and Technology, vol. 22, no. 6, pp. 549-552, 2012.

[2] H. Chuanbo, W. Pu, and G. Zhang, "Numerical simulation of solid liquid two phase flow featuring combination of drainage and fast dredging in mine emergency," Journal of Heilongjiang Institute of Science and Technology, vol. 27, no. 1, pp. 8-25, 2017.

[3] H. A. O. Chuanbo, H. Yu, G. Zhang et al., "Underground geological fault fracture zone of roadway collapse mechanical properties fall," Journal of Heilongjiang Institute of Science and Technology, vol. 26, no. 4, pp. 351-357, 2016.

[4] H. A. O. Chuanbo, H. Yu, G. Zhang et al., "Caving forms of roadway deposit underground geological fault fracture zone," Journal of Heilongjiang Institute of Science and Technology, vol. 26, no. 3, pp. 251-261, 2016.

[5] G. Zhang, W. Li, G. Chen et al., "Simulation study on rescue channel position and section shape selection for accumulation body of collapse-caving," Journal of Heilongjiang Institute of Science and Technology, vol. 27, no. 1, pp. 1-7, 2017.

[6] W. Pu, C. Hao, and G. Zhang, "Congestion characteristics behind slope changing roadway in coal mine water inrush disaster area," Journal of Heilongjiang Institute of Science and Technology, vol. 26, no. 6, pp. 591-595, 2016.

[7] W. Pu, H. Chuanbo, and G. Zhang, "Study on mechanical properties of clogging deposit in mine flood changing slope point of roadway," Journal of Heilongjiang Institute of Science and Technology, vol. 27, no. 1, pp. 26-30, 2017.

[8] H. Yan, J. Zhang, S. Zhang et al., "Macro-micro research on compaction properties of granular backfilling materials," Journal of China Coal Society, vol. 42, no. 2, pp. 413-420, 2017.

[9] H. Yang, W. Xu, and Q. Zhang, "Macro-and mesomechanism of strain localization in granular material," Chinese Journal of Rock Mechanics and Engineering, vol. 34, no. 8, pp. 1692-1701, 2015.

[10] Z. Gao and H. H. Shen, "A study of constitutive model for granular material based on characters of discrete particles arranged," Rock and Soil Mechanics, vol. 30, no. S1, pp. 93-98, 2009.

[11] X. Liang and L. Zheng, "Numerical analysis of stability of debris debris by discrete element method," Railway Engineering, vol. 2, pp. 91-93, 2011.

[12] G. Zhang, C. Hao, H. Yu et al., "Analysis of collapse shape about mining gateway under condition of composite roof after disaster," Journal of Heilongjiang Institute of Science and Technology, vol. 24, no. 1, pp. 6-29, 2014.

[13] S. J. Antony and N. P. Kruyt, "Role of interparticle friction and particle-scale elasticity in the shear-strength mechanism of three-dimensional granular media," Physical Review E, vol. 79, no. 3, 2009

[14] Y. Jiang and M. Liu, "From elasticity to hypoplasticity: dynamics of granular solids," Physical Review Letters, vol. 99, no. 10, 2007.

[15] J. Nielsen, "Pressures from flowing granular solids in silos," Philosophical Transactions of the Royal Society A: Mathematical, Physical and Engineering Sciences, vol. 356, no. 1747, pp. 2667-2684, 2014.

[16] P. T. Metzger, "Htheorem for contact forces in granular materials," Physical Review E, vol. 77, no. 1, 2008.

[17] P. L. Bourdeau, "Stochastic modeling of load-induced settlement in loose granular materials," Journal of Aerospace Engineering, vol. 22, no. 1, pp. 33-42, 2009.

[18] S. Henkes and B. Chakraborty, "Statistical mechanics framework for static granular matter," Physical Reviewe E, vol. 79, no. 6, 2009.

[19] M. R. Kuhn, "Contact transience during slow loading of dense granular materials," Journal of Engineering Mechanics, vol. 143, no. 1, article C4015003, 2015.

[20] T.-T. Ng, "Discrete element method simulations of the critical state of a granular," Material International Journal Of Geomechanics, vol. 9, no. 5, pp. 209-216, 2009.

[21] F. Xiao, G. Liu, Z. Zhang et al., "Acoustic emission characteristics and stress release rate of coal samples in different dynamic destruction time," International Journal of Mining Science and Technology, vol. 26, no. 6, pp. 981988, 2016.

[22] F. Xiao, G. Liu, and Q. Cheng, "Study on mechanical properties and damage evolution law of secondary destruction induced by simultaneous unloading after the peak of the curve of sandstone," Shock and Vibration, vol. 2018, Article ID 9524248, 17 pages, 2018. 
[23] Y. Tong, C. Xu, B. Wang, L. Zhang, and G. Liao, "The cohesive strength and the friction angle in rock-soil triaxial rests," China Mining Magazine, vol. 12, pp. 104-107, 2007.

[24] R. Blumenfeld, J. F. Jordan, and S. F. Edwards, "Interdependence of the volume and stress ensembles and equipartition in statistical mechanics of granular systems," Physical Review Letters, vol. 109, no. 23, 2012. 


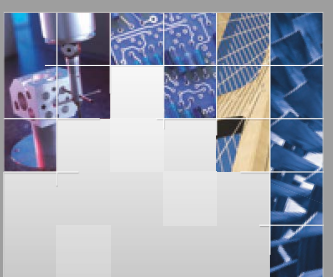

\section{Enfincering}
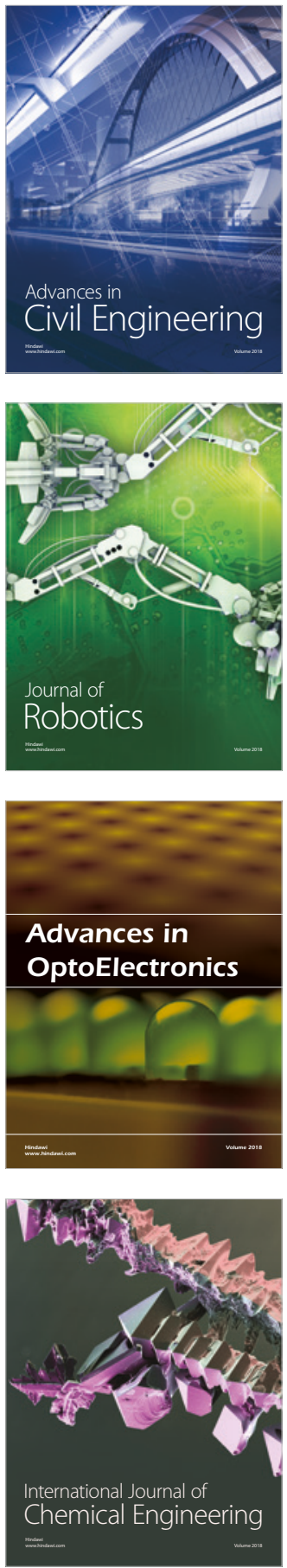

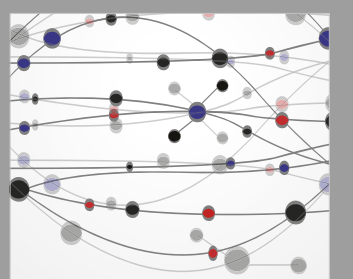

\section{Rotating \\ Machinery}

The Scientific World Journal

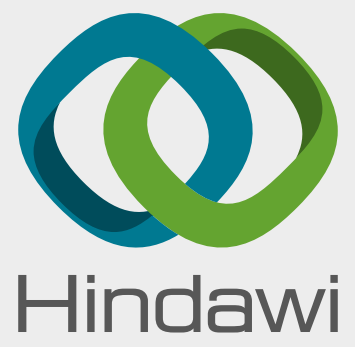

Submit your manuscripts at

www.hindawi.com
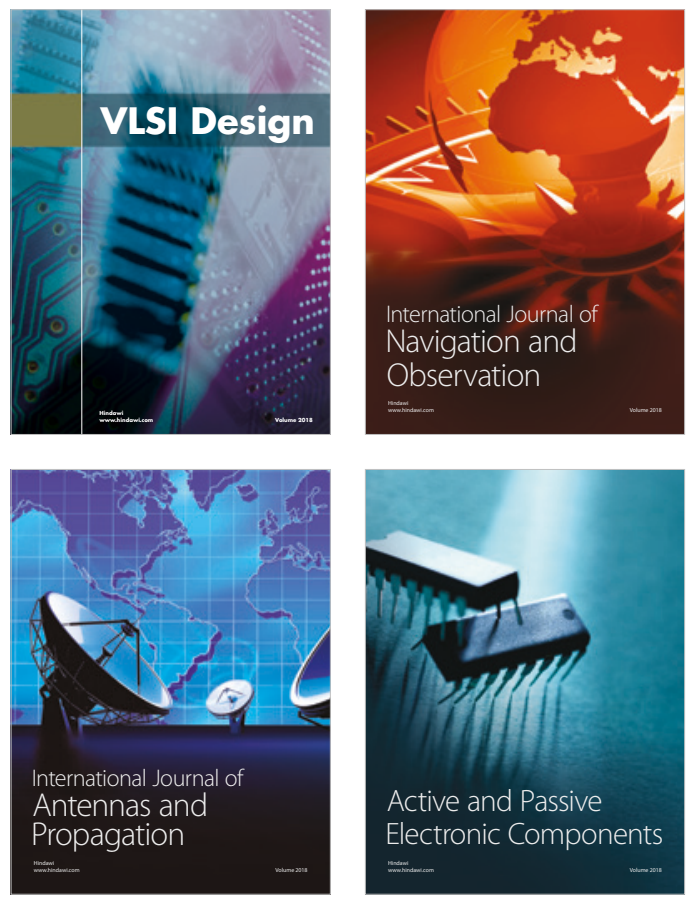
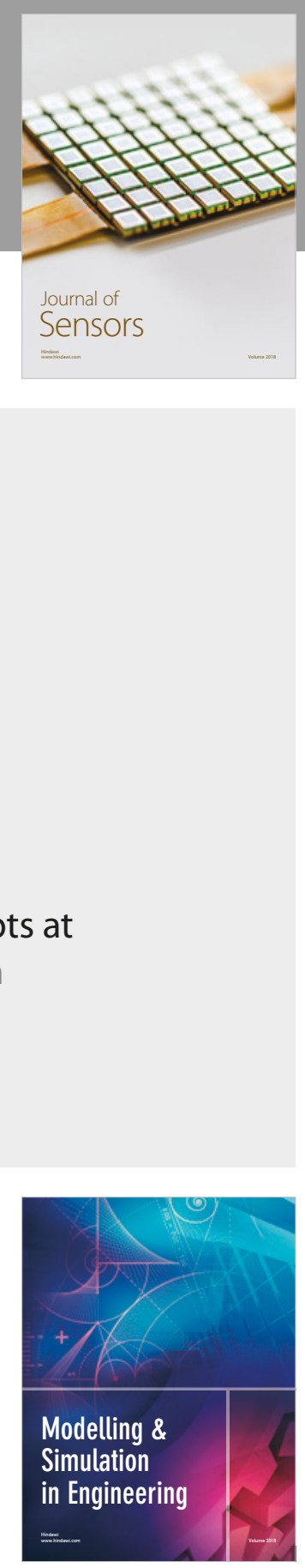

\section{Advances \\ Multimedia}
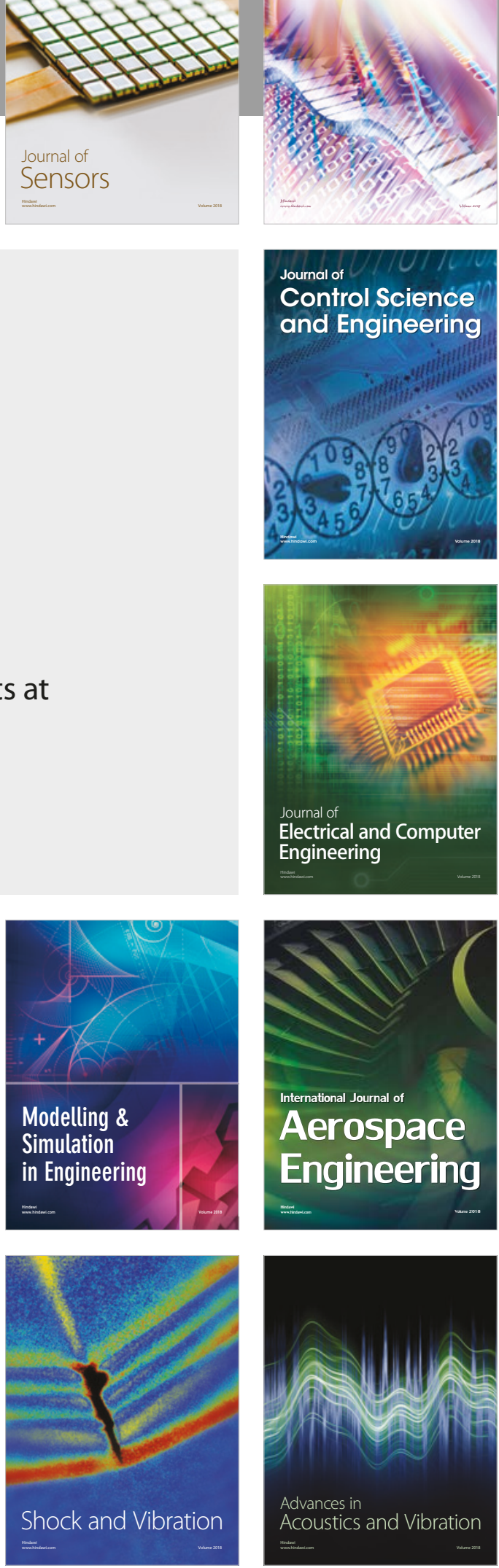